Literature Reviews

\title{
Causes of Early Marriage and Its Effect on Reproductive Health of Young Mothers in Bangladesh
}

\author{
Md. Ruhul Kabir, Susmita Ghosh and Asma Shawly \\ Department of Food Technology and Nutrition Science, Noakhali Science and Technology University, Bangladesh
}

\author{
Article history \\ Received: 25-08-2019 \\ Revised: 25-11-2019 \\ Accepted: 27-11-2019 \\ Corresponding Author: \\ Susmita Ghosh \\ Department of Food \\ Technology and Nutrition \\ Science, Noakhali Science and \\ Technology University, \\ Bangladesh \\ Email: susmita.dristy@gmail.com
}

\begin{abstract}
The ubiquitous nature of early marriage which practiced across all background and social divides in Bangladesh causing a lot of concerns as according to UNICEF report on "The state of world's children 2017" Bangladesh has the fourth highest prevalence rate of child marriage in the world (59\% marriage of women is happened before the age of 18 years). Poverty and low literacy are deciding factors; however, this phenomenon has severe health consequences which most of the times are overlooked and takes for granted in a country like Bangladesh. The study aims on the present situation of early marriage in Bangladesh, its social context and also identifies its effect on reproductive health. The tradition driven by poverty, unwillingness of parents to invest in girl's education, superstition, lack of social security and awareness directly affects girls' education, physical health, psychological well-being and consequently the health of their offspring. Though prohibition of child marriage is legal, but incidents of child marriage are still pervasive, especially in remote areas of Bangladesh due to proper enactment and social insecurity. A study conducted in rural Noakhali, Bangladesh revealed that more than $80 \%$ of marriage happened for women under 18 years of age. A study which found that still birth, miscarriage and pregnancy termination are significantly associated with child marriage. Early marriage often followed by adolescent pregnancies has enormous harmful effect on women's health as they are not ready physically and psychologically, hence increases the risk for different sexually transmitted diseases, obstetric fistulas, pre-term deliveries, miscarriage accompanied by mental depression, physical abuse, lack of social coherence and isolation and so on. To prevent child marriage, focusing on the underlying causes of child marriage is imperative and its serious health consequences warrant proper enactment of legislation and addressing the socioeconomic causes that propitiates child marriage.
\end{abstract}

Key words: Child Marriage, Early Marriage, Social Causes, Reproductive Outcomes, Maternal Mortality

\section{Introduction}

Child marriage (under 18 years) and young age marriage (under 16 years) have lot of concerns because of its overspread nature across societies of different class and status predominantly in developing countries (UNCF, 2005). It is a very common practice in South Asia and Sub-Saharan Africa to give early marriage to their daughters. There are social, psychological and health consequences of early marriage and it will affect both young mother and their children. It is recognized as both human rights violation and social development barrier (ICRW, 2007). Different studies has found that the effect of early marriage is negative and it is detrimental for the young mother and their children and as whole for the community. Teenage mothers have more child and give early birth than their adult peers and hence suffer from long chain of health complications (Raj et al., 2009). Nevertheless it does not stop there because serious health consequences is also experienced by the children of teenage mother. Child of a young mother is prone to die twice times greater than the child of a woman in their twenties (ICRW, 2007). In the event that they endure some way or another, these babies will 
in general have higher paces of low birth weight with inborn oddities, untimely birth and newborn child mortality than those destined to more aged mothers (Save the Children, 2004). Moreover, unconstrained fetus removal, preterm conveyance, Low Birth Weight (LBW), medical issues in new conceived child, defective feeding practices, absence of knowledge with respect to family welfare strategies are found to be associated with child marriage (Pandya and Bhanderi, 2015).

Timing of the first marriage or association is a significant component of woman's reproductive behavior, with sweeping outcomes, especially for their reproductive wellbeing and societal position (Singh and Samara, 1996). Thus, age at marriage plays an important role for reproductive and social outcomes. The negative results related with early marriage and dropping out of secondary school can possibly influence the individual basic decision making as well as children and the remainder of the society (ICRW, 2007). Various obstacles such as the huge household responsibilities, early pregnancy, taking care of their children and other social obstacles restrict the married young girl to take the advantage of education and employment and eventually their own decision making abilities (Mathur et al., 2003).

In Bangladesh, as in numerous different nations of South Asia, early marriage is seriously inescapable and early marriage rate is one of the most elevated on the world (Jones, 2007).

Poverty, protection of girls, family honor and the provision of stability during unstable social periods are predicted to be significant factors in determining the causes of child marriage (UNCF, 2005). Early marriage and early motherhood are the tradition in Bangladesh for many years. In Bangladesh minimum age at marriage for males is 21 years and for female it is 18 years and it is set by the Muslim Family Ordinance 1961 (amended in 1981) of the Bangladesh Government. Though the ordinance is not followed strictly. Additionally, research conducted so far on age at marriage in Bangladesh has focused mainly on examining the customs and factors affecting age of females at first marriage (Chowdhury, 2004; Islam and Ahmed, 1998; Islam and Mahmud, 1996; Naher, 1985).

For in-depth analysis of this serious issue this literature review was aimed to investigate the prevalence, causes and its consequences on various outcomes regarding reproduction among young girls in Bangladesh. Also the analysis tried to find out the basic behavioral differences between rural and urban people regarding child marriage. Function of the Government of Bangladesh and NGOs or development organizations, which are fighting for preventing and responding towards early marriage is also examined in this study. The review process also tried to answer what socio demographic causes affects child marriage and the magnitude of its deep rooted practice.

\section{Child Marriage: A Global Concern}

Marriage before the age of 18 either formal or informal union is called child marriage (UNICEF, 2014). Even though wealthiest and most developed nations also practice child marriage, however due to poverty and lack of economic development, practice of child marriage is prevalent in sub-Saharan Africa, South Asia and parts of Central America (ICRW, 2007). UNICEF (2019) reported that the number of girls and women who married as children are more than 650 million and now 12 million girls are married each year. In developing countries, among seven girls, one will marry at the age of fifteen or even less than fifteen and it is estimated that around 3,500 girls marry before fifteen (UNICEF, 2014) and 21,000 girls before eighteen each day (ICRW, 2007).

\section{Child Marriage Situation in Bangladesh}

With the fertility rate of 2.3 children per woman, Bangladesh is one of the world's densely inhabited countries. About twenty-fifth percent of Bangladeshi women have children before reaching the age of twenty (UNICEF, 2019). There is a widespread gender discrimination in Bangladesh's socio-cultural environment, so girls and women face numerous barriers to their progress and development. Early marriage and early motherhood is a very common scenario in Bangladesh. Again, Bangladesh possesses one of the highest child marriage rates in developing nations (UNCF, 2005). 59\% of women in Bangladesh are married off before the age of 18, as stated by UNICEF's (2017), which was $66 \%$ in the report of 2011. The condition of child marriage in Bangladesh has developed in the past 30 years, but it remains very common in the rural areas and metropolitan slums, particularly among the underprivileged group of people. Sylhet, Chapainawabganj, Rangpur, Jessore, Bhola and parts of Khulna district have the worst situation of early child marriage in Bangladesh. Gazi et al. (2013), a study conducted by icddr,b revealed that $64 \%$ of Bangladeshi women aged between twenty to twenty-four were married off before reaching the legal age of marriage. Rural girls have a high prevalence of early marriage and $73 \%$ of them got married before they reached the age of 18. One the other hand, $27 \%$ of the rural girls got married between the ages of 12 and 14 (Plan International, 2015). Another study carried out in rural areas of Noakhali District found out the rate of early marriage was more than $80 \%$ and at least $20 \%$ of them had children before the age of 18 years (Kabir et al., 2019). In Bangladesh, there is a tendency to look over the negative consequences associated with early marriage. Moreover, village girls are scarcely consulted with when it comes to their marriage. Plan International has discovered that deeply entrenched cultures and beliefs are to blame for early marriage in Asia. 


\section{Human and Children's Rights in Bangladesh}

Though the legal marital age for girls and boys is 18 and 21 respectively as legislated by the Child Marriage Restraint Act (1929), Girls from Bangladesh are typically married at 16.4 years of age, as identified by the Bangladesh Demographic and Health Survey (UNICEF, 2017). This Act provides punishments for those who marry children, solemnize child marriage and authorize it. According to this legislation, the punishments for child marriage are confinement for one month or a fine up to taka 1000 or both. Though there are many national laws and international treaties, early marriage continues to be a widespread problem, especially in developing countries like Bangladesh. This practice is more predominant in village people which create an interference to the well-being and future possibilities of millions of girls (Mizanur, 1999; Nasrin and Rahman, 2012).

\section{Role of Bangladesh Governments and Different NGO's}

The Government of Bangladesh has already established laws, regulations and preventive attempts for inhibiting early marriage. It appears that the actions of the Government both at the national and the regional level have not drawn significant progress yet. However, local government tries to intervene child marriage if information reaches out to them. Besides awareness creation about the significance of eradicating child marriage and putting legislation in place, campaign for birth registrations has introduced by governments. The Bangladesh Birth Registration Act was revised in 2004 and the law makes it mandatory for each bride and groom to have a birth certificate before they can register their marriage. The government is also making attempts to broadcast the message about birth registration through TV and public awareness campaigns (BITA, 2007; Unnayan Onneshan, 2011). Furthermore, Bangladesh has committed to eradicate child, early and forced marriage by 2030 to meet the terms of Sustainable Development Goals. During its Voluntary National Review at the 2017 High Level Political Forum, the government noted that women's empowerment plays a prominent role in the Constitution of Bangladesh, the National Women Development Policy and the Child Marriage Restraint Act (Girls Not Bride, 2019). A very admirable role is being played by NGOs to prevent early marriage. Some community-based approaches are being taken successfully by a large number of NGO's to postpone early marriage among adolescent girls. Many national and international organizations such as Care Bangladesh, Oxfam, Voluntary Health Services (VHSS), Bangladesh Population and Health Consortium (BPHC), Action Aid
Bangladesh, Population Council, Save the ChildrenUSA, UNICEF and Plan International are operating as a source of funding and technical support to approximately 100 organizations with plans and programs regarding the betterment of adolescent girls such as birth registration, early marriage, dowry prevention and so on. After recognition of the dreadful outcomes of child marriage, many organizations are taking up global and national level programs (Unnayan Onneshan, 2011).

\section{So what are the Influencing Factors to Initiate Child Marriage in Bangladesh?}

According to the studies carried out to discover the factors that have effects on early marriage in Bangladesh, the following circumstances draw out the most attention:

The most leading reasons for such high incidences of child marriage is lack of employment and economic opportunities followed by overspread poverty (Gazi et al., 2013). The median age of marriage for girls who live in the poorest households of Bangladesh is 15 , compare to 18 for those who live in the richest households (Girls Not Bride, 2019). To ensure their daughter's future, underprivileged families often offer marriage to their daughter (BITA, 2007).

Some families may believe, early marriage as financially beneficial due to the increased cost of dowry as a girl gets older. Hence, if the families can marry off their daughters, they don't have to support their child financially anymore (Plan International, 2015; Girls Not Bride, 2019).

\section{Gender Discrimination}

Gender inequality is one of the driving factors for child marriage. Communities from the different regions of the world support norms and customs that cause discrimination against women and girls. Bangladesh is the country where male child is considered as source of income and female child is considered as economic burden. In order to release this burden, parents of female child found marriage as a solution. Therefore, early marriage also promotes gender inequity since young brides have no equality in their marriages (Plan International, 2015; Nasrin and Rahman, 2012).

\section{Cultural Norms, Social Safety and Provocation}

One of the leading causes of child marriage is acquired from cultural norms and their corresponding social pressure. Girls' marriage is seen as an essential and inevitable process by everyone and it is regarded as a major parental responsibility nowadays. It is also the responsibility of the parents to protect the chastity of the daughter until she gets married (Plan International, 
2013). That is the main reason when a girl attains puberty, parents feel it is the right time to discharge their 'duty' and marry their daughter. Social stigma adds to the responsibility of the parents for the marriage of a daughter, particularly when a girl starts looking mature (Plan International, 2013). According to a 17-year old girl who participated in the research conducted by Plan International in Bangladesh: "If a girl doesn't get married people will start to gossip about her. She will lose her reputation and people will think she is having affairs. For a man, it is less of an issue. He can remain single (Plan International, 2015)"

\section{Impact of Proper Formal Education}

Other than poverty, child marriage is associated with illiteracy and lack of access to education (Plan International, 2015; Girls Not Bride, 2019; UNESCO, 2010). Among Bangladeshi women who do not have formal education, the median age of marriage is 15 compared to 20 for those who have completed secondary education or higher. (Girls Not Bride, 2019). Marriage of girls generally associates with low levels of education, or no education at all (IPPF, 2008). Bangladesh has cultural settings where girls are raised for a lifetime restriction to household occupations and are expected to marry at very young age. So to fulfill the social stigma, many girls drop out from school at a very early age. Marriage is often considered as an alternative for illiterate girls who do not have any choices for the future (World Vision, 2008). Besides, uneducated parents are less likely to be aware of the laws forbidding child marriage and the consequences connected with the malpractice than educated parents. Illiteracy and early motherhood typically results in a lack of decision-making power, which makes the girls vulnerable to violence and injustice (ICRW, 2012).

\section{Non-Enforcement of the Law}

Bangladesh has made it compulsory to present a birth certificate at the time of marriage (Girls Not Bride, 2019). However, because of weak enforcement mechanism or inadequate application of remaining laws, child marriage remains without getting proper punishments (Plan International, 2015; de Silva-de-Alwis, 2008).

Laws are available but enforcement is inadequate because Laws can only be executed if cases are reported and resolved by the legal system, but this often does not occur because of a lack of awareness of national laws and because children are usually married with their parents ' approval (UNICEF, 1998). Practices of child marriage, which usually violate national laws, are progressing because many jurisdictions do not have a reliable system for registering marriages (UNICEF, 1998).

\section{How Child Marriage Affects Reproductive Health?}

\section{Depression and Feeling Alone}

Because of childhood marriage, a girl often find herself in a state of distress since she is still in her puberty and in that process losses her childhood, chances of being educated and make friends. The pressure to reproduce at young age is also a common phenomenon and sometimes if unable to get pregnant then the husband rarely hesitate to marry again (Nour, 2006). Forced sexual intercourse and the denial of free will and social development resulting from early marriage have serious psychosocial and emotional consequences that often adversely affect the life of the young bride (UNCF, 2005).

\section{Sexually Transmitted Diseases and increased cancer risks}

Early marriage puts girls under major threats of different sexually transmitted diseases and those girls who got married early will have long-married and sexual life thus they are more prone to develop STDs than women who married later. Evidence suggests that a very deadly disease, named cervical cancer caused due to polygamy and early marriage (Nour, 2006). Research in Morocco had findings that indicate child marriage, high parity, long-term use of oral contraceptives and poor genital hygiene are risk factors of cervical cancer (Chaouki et al., 1998).

\section{Children Bearing and Delivering Children; A Major Consequence of Early Marriage}

Early marriage is responsible for early pregnancy. Many challenges have to face by the girls who got pregnant at a very early age. As early pregnancy suppresses the immune system, the young girls possess a high risk of acquiring diseases like malaria. In addition to being most vulnerable to malaria during their first pregnancy (Staalsoe et al., 2004), pregnant women also have higher rates of malaria-associated complications (particularly pulmonary edema and hypoglycemia) and death than non-pregnant women. The density of Malaria parasite is much higher in pregnant girls $<19$ years than in pregnant women $>19$ years (Brabin and Brabin, 2005).

A study conducted in the South Asian countries including Bangladesh, revealed that lower contraceptive use, poor fertility outcome and poor maternal well-being are some factors that are significantly correlated with child marriage. Usage of contraceptive methods was not very common in women who were married as children. Lower fertility control can lead to adverse fertility outcomes such as termination of pregnancy and unplanned pregnancy (Godha et al., 2013). In another 
study carried out in Bangladesh to identify the association between child marriage and preterm birth considering pregnancy weight gain as mediator showed a small but statistically significant indirect effect on preterm birth $(\mathrm{RR}$ indirect effect $=1.02 ; 95 \% \mathrm{CI}$ : 1.00,1.05) (Rahman et al., 2018). A study which was based in BDHS 2011, showed that still birth, miscarriage and pregnancy termination are significantly associated with child marriage and it was also found that $70.4 \%$ and $23.4 \%$ women who got early marriage had still birth and pregnancy termination which were greater than that women who married after getting adult (Kamal and Hassan, 2015).

Another study found that the majority of the married adolescent girls had lower awareness of maternal healthcare including ANC, hospital delivery and PNC care. Researchers also revealed that the perceived health care needs of girls during pregnancy and childbirth affected their use of skilled maternal health services. As most of the adolescent girls thought pregnancy as a natural phenomenon, they did not consider hospital delivery and medical check-ups necessary unless they suffered from any complication (Shahabuddin et al., 2017).

The problem with early pregnancy is that the young mothers are at a remarkably higher risk than older women for debilitating sickness and even death (ICRW, 2012). Eclampsia, malaria postpartum hemorrhage, HIV infection and obstructed labor are the causes of high death rates. Girls 10-14 years of age are 5 to 7 times more likely to die from childbirth compared to women $>$ 20 years of age and girls 15-19 are twice as likely to die from childbirth (UNICF, 2005).

Girls aged 10-15 years are particularly vulnerable as their pelvic bones are not fit for childbearing and delivery. Their chance for fistula is very high (approximately $88 \%$ ). Once a fistula has been formed, it can result in fecal or urinary incontinence and peroneal nerve palsy, leading to humiliation, ostracism and depression. These girls can only live a normal life if the fistula is repaired surgically (UNCF, 2005).

\section{High Rate of Maternal Mortality}

The maternal mortality rate in Bangladesh is one of the highest in the region. The government of Bangladesh estimates that there are 320 maternal deaths per 100,000 live births (NIPORT, 2014). The high rate of unattended home births, the high prevalence of pregnancy among adolescent girls and high incidence of malnutrition are the main influencing factors to the shocking maternal mortalityrate (ICRW, 2012). Pregnancy related deaths are the world's leading cause of death for girls aged 1519 (ICRW, 2012). Southern Asian girls aged 15 and 19 years are more likely to die from complications during pregnancy and childbirth than women between 24 and 29 years of age (Save the Children, 2012).

\section{Effects on Children}

Child marriage affects not only the young girls but also the next generation. Adolescent mothers possess a $35-55 \%$ higher risk than older women for delivering preterm and low birth weight infants. Among children born to mothers under 20 years of age, mortality rates are $73 \%$ higher than those born to older mothers. Chlamydia, syphilis, gonorrhea and herpes simplex virus infection are some untreated sexually transmitted diseases which can have deleterious effects on neonates, such as premature delivery, congenital neonatal infections and blindness. Moreover the mortality rate for children $<5$ years can be $28 \%$ higher for children born to young mothers than for those born to mother $>20$ years (Bicego, 1996). Problems for children correspond with young mothers, including low birth weight and malnourished babies which is responsible for significant physical and cognitive defects in adulthood (Plan International, 2013). Both adolescent mothers and children are vulnerable to anemia and anemia is reported to be a serious public health issue with $30 \%$ of adolescent girls compared to $26 \%$ of adolescent boys and nearly half of all pregnant women (UNICEF Bangladesh, 2009).

\section{HIV Risk}

Married girls are more prone to sexually transmitted diseases, particularly HIV and human papilloma virus. As girls have to demonstrate their fertility, they had highfrequency, unsafe intercourse with their partners. In most of the cases, their older husbands had former sexual partners, or in many cases they were polygamous. Besides, the girls' virginal status and physical immaturity raise the risk of HIV transmission secondary to hymenal, vaginal, or cervical lacerations (Nour, 2006). Globally, the prevalence of HIV infections among women between the ages of 15 and 24 is highest; the risk for men peaks 5-10 years later (Laga et al., 2001). It has been found that only $16 \%$ of girls aged between 15 and 24 in Bangladesh have a comprehensive knowledge of HIV (Nour, 2006).

Many men in developing nations assume that having sexual intercourse with a "fresh girl" would cure their sexually transmitted disease. They, therefore, find a young girl to marry, unaware that they would only transfer the disease on to the bride and her child. In addition to health risks and a vicious cycle of poverty, child marriage often causes brides to attempt and commit suicide because of the social, physical and emotional violence they face in their marital home (Roy and Sarker, 2013).

\section{Discussion}

In most communities where childbirth is not acceptable without marital bond, marriage is an occasion of renowned social and cultural importance for women and men. However, marriage before the physical and 
mental maturation puts girls under tremendous pressure and this has been the common practice in Bangladesh (Kamal, 2012). The analysis of overspread prevalence of child marriage in Bangladesh brings pinpoint that child marriage has profound health, social, economic and political implications for the girl and her family. Child marriage snatches off the childhood of a girl and thus creates severe physical and psychological health risks and robs her globally accepted human rights. Evidences suggest it is crying need to put special attention to this phenomenon regarding its causes: Lack of access to financial opportunity, education and health services, especially for girls, along with severe poverty, inadequate legal and enforcement mechanism and most disturbingly, the normalization and approval of male sexual violence and extreme gender inequity (Plan International, 2015). The most important determinant of child marriage in Bangladesh is Women's education. Hence, a lower incidence of early marriage is correlated with higher education of the respondents (Kamal, 2011). The women who have achieved higher education would generally have a higher career ambition and would like to have jobs that are appropriate for them rather than marrying earlier. Because of long-term schooling and a desire to build a career, more educated women are more likely to marry later than others. This suggests that girls should be held for longer periods in class, not only to postpone their marriage but also for physiological, mental and physical maturity (Kamal, 2011). Moreover, evidence suggests that educating girls about their rights and skills for modern livelihoods can decrease the chances of child marriage by up to one third in Bangladesh (Girls Not Bride, 2019).

Women economic dependence and lack of health service facilities also play strong roles. Lack of income opportunities, poverty and insecurity encourage families to marry off their female child as early as possible which loads off some of the burden of the family (Plan International, 2015; Nour, 2006). In the majority cases, early marriage is linked with early childbirth and rearing, especially in developing countries where the primary objective of marriage is to have children (Laga et al., 2001). In Bangladesh, Women want to have a child as early as possible to confirm their fertility. In rural areas where illiteracy and poverty are predominant, women are blamed if she makes a delayed decision of having a child. Additionally, early exposure to sexual life and immature physical dimensions put girls under severe health risks including risk of developing deadly sexually transmitted diseases of different kinds (UNICEF, 1998). The higher likelihood of child mortality among married adolescent girls can be associated not only to physical and biological maturity but also partly to longer marital life. Early marriage is also responsible for other maternal risk factors associated with negative birth outcomes
(Ikamari, 2005). Studies on how early marriage affects reproductive health revealed that early exposure to sexual life leads women more likely to have different sexually transmitted diseases, pre-term deliveries, pregnancy complications, complications during child birth and so on (Rahman et al., 2018; Kamal and Hassan, 2015). Moreover, poor adoption of family planning, low utilization of contraceptives, poor caring practice of child are also seen to be connected with early marriage. The correlation between early teenage pregnancy and adverse birth outcomes indicates the deleterious socio-demographic environment. Researches also showed that young maternal age plays an independent risk factor for adverse birth outcomes and the risk factor also attributes to other factors that are associated with teenage pregnancy, such as low socioeconomic status, ethnicity and inadequate prenatal care (Yoder and Young, 1997; Rogers et al., 1996).

Enforcement and implementation of laws against child marriage are often ineffective. Governments need to take responsibility for stopping this tradition through media campaigns and education outreach plans and programs. Local, regional and national governments can also carry out health outreach programs for both girls and boys. Women will be encouraged to negotiate safer sex, if they are provided knowledge about proper reproductive and sexual health, STD prevention, contraception, AIDS and health-seeking behavior.

Ending child marriage demands a multilateral strategy focused on the girls, their families, the society and the government. Appropriate plans and programs that provide education and reproductive health services for families and communities can help to stop child marriage, early pregnancy and disease and death in young mothers and their children (Plan International, 2015; Girls Not Bride, 2019). Changing communities' perspectives is not an impossible challenge. Improved education and training, economic opportunity, access to health services and stricter constitutional frames can make a visible difference to the levels of agreement and predominance of child marriage in a country like Bangladesh.

\section{Conclusion}

Early marriage has been a long term practice in Bangladesh. Two crucial factors for early marriage are poverty and illiteracy. Miscarriage, still birth, abortion, pre-term delivery, low birth weight baby, complications during delivery and poor attention to her own health and child upbringing are some of health issues that are propitiated by early marriage. The pervasiveness of child marriage and its relationship with higher fertility and lower control of fertility-factors linked to various poor maternal and child health outcomes-promotes the urgent need for maintaining proper marriage laws and regulation along with strong determination of 
governments, civil societies and communities to work in tendon to face this national as well as global crisis.

\section{Recommendation}

The reason for early marriage is more social and economic rather than legal which has been stated by many studies that involve child marriage. Eradication of poverty can be a way forward in this situation along with putting effort on addressing social factors which has been stated in the paper. Regulation of marital age, compulsory marriage registration, strengthening birth registration system and proper enactment of law can be effective and preventive to the child marriage. Moreover, it is needed to expand girl's education facilities, especially at secondary level and women empowerment might also help the cause. Reproductive health outcomes that arise from early marriage should be addressed accordingly and therefore, health service department may provide health knowledge on family planning, proper and timely use of contraceptives as well as other basic information not only to girls but also the other members of a family.

\section{Conflict of Interest}

The authors declare no conflict of interest.

\section{Sources of Financial Support}

There is no funding to be mentioned.

\section{Submission Declaration}

The authors declare that the paper is not under consideration for publication elsewhere.

\section{Ethical Approval}

Since the study is based on review of existing literature therefore no ethical permission was needed.

\section{Authors Contributions}

All the authors contributed equally.

\section{References}

Bicego, G., 1996. Demographic and health surveys comparative studies, no. 20. Infant and Child Mortality, Macro International, Calverton (MD).

BITA, 2007. Marriage in Bangladesh: When it is too early. Bangladesh Institute of Theatre Association.

Brabin, L. and B.J. Brabin, 2005. HIV, malaria and beyond: Reducing the disease burden of female adolescents. Malaria J., 4: 2-2.

DOI: $10.1186 / 1475-2875-4-2$
Chaouki, N., F.X. Bosch, N. Muñoz, C.J. Meijer and B. El Gueddari et al., 1998. The viral origin of cervical cancer in Rabat, Morocco. Int. J. Cancer, 75: 546-554. DOI: $10.1002 /($ SICI $) 1097-$ 0215(19980209)75:4<546::AID-IJC9>3.0.CO;2-T

Chowdhury, F.D., 2004. The socio-cultural context of child marriage in a Bangladeshi village. Int. J. Soc. Welfare, 13: 244-53. DOI: $10.1111 / \mathrm{j} .1369-6866.2004 .00318 . \mathrm{x}$

de Silva-de-Alwis, R., 2008. Child marriage and the lawlegislative reform initiative paper series. UNICEF Working Paper, Division of Policy and Planning.

Gazi, R., Q. Nahar, H. Kabir, M.H. Huque and M. Moinuddin et al., 2013. Child marriage in Bangladesh: Findings from a national survey 2013. icddr,b and Plan International.

Girls Not Bride, 2019. Girls not bride. Bangladesh.

Godha, D., D.R. Hotchkiss and A.J. Gage, 2013. Association between child marriage and reproductive health outcomes and service utilization: A multicountry study from South Asia. J. Adolescent Health, 52: 552-558. DOI: 10.1016/j.jadohealth.2013.01.021

ICRW, 2007. New Insights on Preventing Child Marriage: A Global Analysis of Factors and Programs. 1st Edn., International Center for Research on Women, Washington, DC, pp: 53.

ICRW, 2012. Child marriage in Southern Asia: Policy options for action. International Center for Research on Women (ICRW), United Nations Population Fund (UNFPA), Australian Agency for International Development (AusAID), Asian Forum of Parliamentarians on Population and Development (AFPPD).

ICRW, 2012. Child marriage in Southern Asia: Policy options for action. International Center for Research on Women (ICRW), United Nations Population Fund (UNFPA), Australian Agency for International Development (AusAID), Asian Forum of Parliamentarians on Population and Development (AFPPD).

Ikamari, L., 2005. The effect of education on the timing of marriage in Kenya. Demographic Res., 12: 1-28. DOI: 10.4054/DemRes.2005.12.1

IPPF, 2008. Ending child marriage: A guide for global policy action17. International Planned Parenthood Federation.

Islam, M.M. and M. Mahmud, 1996. Marriage patterns and some issues related to adolescent marriage in Bangladesh. Asia-Pacific Populat. J., 11: 27-42. DOI: $10.18356 / 9$ cb1963c-en

Islam, M.N. and A.U. Ahmed, 1998. Age at first marriage and its determinants in Bangladesh. AsiaPacific Populat. J., 13: 73-92. DOI: $10.18356 / f 31 b 417$ e-en 
Jones, G.W., 2007. Fertility decline in Asia: The role of marriage change. Asia-Pacific Populat. J., 1: 22-22. DOPI: 10.18356/d39a54f1-en

Kabir, M.R., S. Ghosh, A.A. Mamun, H. Islam and R.B.A. Ghani, 2019. Factors associated with antenatal and health facility delivery care in selected areas of Subornochor upazilla, Noakhali, Bangladesh.

Kamal, S.M. and C.H. Hassan, 2015. Child marriage and its association with adverse reproductive outcomes for women in Bangladesh. Asia Pacific J. Public Health, 27: NP1492-NP506.

DOI: $10.1177 / 1010539513503868$

Kamal, S.M., 2011. Socio-economic determinants of age at first marriage of the ethnic tribal women in Bangladesh. Asian Populat. Stud., 7: 69-84.

DOI: $10.1080 / 17441730.2011 .544906$

Kamal, S.M., 2012. Decline in child marriage and changes in its effect on reproductive outcomes in Bangladesh. J. Health Populat. Nutrit., 30: 317-317. DOI: 10.3329/jhpn.v30i3.12296

Laga, M., B. Schwärtlander, E. Pisani, P.S. Sow and M. Caraël, 2001. To stem HIV in Africa, prevent transmission to young women. Aids, 15: 931-934. DOI: 10.1097/00002030-200105040-00014

Mathur, S., M. Greene and A. Malhotra, 2003. Too young to wed. The lives, rights and health of young married girls. International Center for Research on Women, Washington, DC.

Mizanur, M., 1999. Female adolescent marriage among the slum dwellers of Dhaka City. J. Preventive Soc. Med.

Naher, M.S., 1985. Marriage patterns: Customs and changes in rural Bangladesh. J. Soc. Stud., 10: 34-45.

Nasrin, S.O. and K.M. Rahman, 2012. Factors affecting early marriage and early conception of women: A case of slum areas in Rajshahi City, Bangladesh. Int. J. Sociol. Anthropol., 4: 54-62.

DOI: $10.5897 / \mathrm{IJSA} 11.145$

NIPORT, 2014. Bangladesh demographic and health survey. Mitra and Associates and ICF International.

Nour, N.M., 2006. Health consequences of child marriage in Africa. Emerg. Infect. Dis., 12: 1644-1644. DOI: 10.3201/eid1211.060510

Pandya, Y.P. and D.J. Bhanderi, 2015. An epidemiological study of child marriages in a rural Community of Gujarat. Indian J. Community Med., 40: 246-251. DOI: 10.4103/0970-0218.164392

Plan International, 2013. 'Child marriage in Bangladesh'. Plan International.

Plan International, 2015. New evidence on child marriage causes and solutions. Plan International.
Rahman, M.L., M.L. Kile, E.G. Rodrigues, L. Valeri and A. Raj et al., 2018. Prenatal arsenic exposure, child marriage and pregnancy weight gain: Associations with preterm birth in Bangladesh. Environ. Int., 112: 23-32. DOI: 10.1016/j.envint.2017.12.004

Raj, A., N. Saggurti, D. Balaiah and J.G. Silverman, 2009. Prevalence of child marriage and its effect on fertility and fertility-control outcomes of young women in India: A cross-sectional, observational study. Lancet, 373: 1883-1889.

DOI: 10.1016/S0140-6736(09)60246-4

Rogers, M.M., M.D. Peoples-Sheps and C. Suchindran, 1996. Impact of a social support program on teenage prenatal care use and pregnancy outcomes. J. Adolescent Health, 19: 132-140. DOI: 10.1016/1054-139X(95)00227-J

Roy, I. and A.K. Sarker, 2013. Early marriage impact on female's health and their satisfactory level: A distinctive analytical study in Bangladesh. Int. J. Sci. Res., 5: 363-369.

DOI: $10.21275 / \mathrm{v} 5 \mathrm{i} 3 . \mathrm{NOV} 161827$

Save the Children, 2004. State of the World's Mothers 2004: Children having Children. 1st Edn., Save the Children, Westport, CT, pp: 38.

Save the Children, 2012. Every woman's right: How family planning saves children's lives. Save the Children.

Shahabuddin, A., C. Nöstlinger, T. Delvaux, M. Sarker and A. Delamou et al., 2017. Exploring maternal health care-seeking behavior of married adolescent girls in Bangladesh: A social-ecological approach. PloS One, 12: e0169109-e0169109. DOI: 10.1371/journal.pone.0169109

Singh, S. and R. Samara, 1996. Early marriage among women in developing countries. Int. Family Plann. Perspectives, 1: 148-75. DOI: 10.2307/2950812

Staalsoe, T., C.E. Shulman, J.N. Bulmer, K. Kawuondo and K. Marsh et al., 2004. Variant surface antigenspecific IgG and protection against clinical consequences of pregnancy-associated Plasmodium falciparum malaria. Lancet, 363: 283-289. DOI: 10.1016/S0140-6736(03)15386-X

UNCF, 2005. Early Marriage: A Harmful Traditional Practice; a Statistical Exploration. 1st Edn., United Nations Children's Fund, New York, pp: 40.

UNESCO, 2010. Education for all global monitoring report: Reaching the marginalized. UNESCO.

UNICEF Bangladesh, 2009. Situation assessment and analysis of children and women in Bangladesh. UNICEF Bangladesh.

UNICEF, 1998. Dow, unity, birth registration: The first right, the progress of nations. UNICEF, New York. 
UNICEF, 2014. Child protection from violence, exploitation and abuse. United Nations Children's Fund.

UNICEF, 2017. State of the world's children report. United Nations Children's Fund.

UNICEF, 2019. Child marriage around the world. United Nations Children's Fund.

Unnayan Onneshan, 2011. The innovators, gender inequality in Bangladesh. Unnayan Onneshan.
World Vision, 2008. Before she's ready: 15 places girls marry by 15 10-11. World Vision.

Yoder, B.A. and M.K. Young, 1997. Neonatal outcomes of teenage pregnancy in a military population. Obstetrics Gynecol., 90: 500-506.

DOI: 10.1016/S0029-7844(97)00357-8 